\title{
Adapting to Involuntary, Radical, and Socially Undesirable Career Changes
}

\author{
Cort W. Rudolph ${ }^{1} \&$ Hannes Zacher ${ }^{2}$ \\ ${ }^{1}$ Department of Psychology, Saint Louis University \\ ${ }^{2}$ Institute of Psychology - Wilhelm Wundt, Leipzig University
}

This is a pre-press version of an in-press, accepted manuscript. Please cite as:

Rudolph, C. W. \& Zacher, H. (2021, in press). Adapting to involuntary, radical, and socially undesirable career changes. Current Psychology. doi: 10.1007/s12144-021-01859-5

\section{Author Note}

Cort W. Rudolph (iD https://orcid.org/0000-0002-0536-9638

Hannes Zacher (D) https://orcid.org/0000-0001-6336-2947

The authors would like to thank Amelie Draws for her help with this study.

Correspondence concerning this article should be addressed to Cort W. Rudolph, Saint Louis University, Morrissey Hall 2827, St. Louis, MO, 63103, cort.rudolph@health.slu.edu, $+1(314) 977-7299$ 


\begin{abstract}
Career adaptability is a psychosocial resource that aids in coping with current and anticipated tasks, transitions, and traumas that people experience in their occupational roles. Although there is a great deal of evidence that career adaptability relates to important career outcomes, the role that it is perceived to play in involuntary, radical, and socially undesirable career changes is understudied. Grounded in career construction theory, we conducted a study with an experimental vignette methodology to ascertain whether career adaptability moderates the influence of different types of career transitions on ratings of hypothetical employees adapting effectiveness. Findings suggest that career adaptability can be seen as an important resource for managing radical career changes. This is one of the first papers to test a key tenet of career construction theory - that career adaptability is efficient for managing career related transitions and traumas. Moreover, we extend the scope of this tenet to include the notion that people can readily identify qualities of career adaptability in others.
\end{abstract}

Keywords: Career Adaptability; Career Change; Experimental Design; Career Construction Theory 


\section{Adapting to Involuntary, Radical, and Socially Undesirable Career Changes}

Career change can be a source of significant stress for individuals (Latack, 1984). Still, people routinely navigate even involuntary, radical, and socially undesirable career changes efficiently (Young \& Rodgers, 1997), and see benefits to their wellbeing (Rigotti et al., 2014) and career success (Chudzikowski, 2012) whilst doing so. To this end, one important question has increasingly received attention in this literature, specifically, "What factors predict relative success in the process of managing radical career changes?" (Zacher, 2018). Research and theory have posited that a network of psychosocial resources classified as "career adaptability" can help individuals successfully adapt to career changes. Embedded within career construction theory (Savickas, 1997, 2002, 2005) and, in particular, the model of adaptation (Savickas et al., 2009), career adaptability has been proposed to serve as a self-regulatory resource, helping employees manage work-related demands and changes (Savickas, 1997).

However, despite the fact that career construction theory posits that career adaptability is a useful resource for supporting the process of career change, this theoretical assumption has rarely been tested, leaving a core tenet of this perspective open for investigation. Career adaptability is formally defined as a "... psychosocial construct that denotes an individual's resources for coping with current and anticipated tasks, transitions, [and] traumas in their occupational roles" (Savickas \& Porfeli, 2012, p. 662). As a core construct in career construction theory (Savickas, 1997, 2002, 2005, 2013), the concept of career adaptability has numerous implications for the field of vocational psychology, broadly defined (see Brown \& Lent, 2016, for a review).

Recent meta-analyses have shown that high levels of career adaptability and its four dimensions (i.e., concern, control, curiosity, and confidence) are associated with favorable work and career outcomes (Rudolph et al., 2017a; Rudolph et al., 2017b). However, research 
concerning career adaptability is limited in that it has not investigated the external conditions under which career adaptability is most useful. Moreover, the vast majority of research on career adaptability has used cross-sectional survey designs, which do not allow for strong inferences about causality.

Given these observations, we conducted the present study to address two relevant goals. First, although career construction theory offers that career adaptability is an important resource in career transitions, as suggested by Rudolph et al. (2017b), there is little evidence about how career adaptability interacts with career tasks and demands, challenges, transitions, or traumata to predict work outcomes. Moreover, there is no research to date that has considered how people external to those undergoing career transitions recognize the importance that career adaptability plays in managing the demands of such transitions. This is important, because career counselors are often tasked with helping their clients to recognize psychological resources that are available to them during career transitions (e.g., Heppner et al., 1994). Moreover, research has shown that those experiencing career transitions often turn to others for social support (e.g., their friends or family; Eby \& Buch, 1995). Thus, understanding others' role in this process, especially how others recognize and make sense of career transitions and assess their (relative) success, is particularly important.

Rudolph et al. (2017b) further argued that studying interactions between career adaptability and career dynamics would provide stronger tests of the core tenets of career construction theory than considering main effects alone. To answer this call, we examined career adaptability as a moderator of the effects of different features of career changes (i.e., involuntariness, radicality, and social undesirability) on ratings of hypothetical employees’ adapting effectiveness (i.e., ratings of how effectively one is coping with career change). We focus on ratings of adapting effectiveness, as it represents an important theoretical mechanism in 
the stress-coping model of career change (i.e., Latack, 1984; Latack et al., 1995). Moreover, these are the types of judgements that, for example, might inform narratives between career counselors and their clients who are facing career changes (e.g., Blustein et al., 2013; Savickas et al., 2009).

Second, most research concerning career adaptability has thus far been observational (e.g., cross-sectional or multi-wave survey designs). One exception is a study conducted using an experimental vignette methodology by Ohme and Zacher (2015), which examined relative effects of hypothetical employees' career adaptability, general mental ability, and conscientiousness on job performance ratings. Results showed that career adaptability influenced job performance ratings above and beyond established predictors of performance. Moreover, this study additionally investigated job complexity as a moderator of these effects, finding that only general mental ability, but not career adaptability or conscientiousness, had a stronger effect on performance ratings when job complexity was high. As suggested by career construction theory, career adaptability should be an especially important resource for people facing potential career challenges and barriers (see Savickas, 1997, 2013), including career changes. Despite this, there is relatively little direct empirical evidence in the literature supporting this notion. Moreover, it is unclear whether people readily recognize that career adaptability behaviors would serve in a resourceful capacity to support others' career transitions.

As suggested, understanding people's capacity to recognize career adaptability behaviors in others is important for a variety of reasons, not least of which is helping career counselors build the capacity to provide guidance to their clients. Thus, the findings of this study could be useful in the development of training programs for career counselors. Our study thus aims to extend previous research by specifically addressing these gaps in our understanding of the role of career changes in the adaptation process implied by career construction theory. This work 
therefore provides needed innovation in the development of career construction theory by empirically addressing a thus-far understudied tenet of this model.

Next, we consider more closely the role that career adaptability and career transitions play in career construction theory. Then, grounded in this theory, we review previous research on career adaptability and career change, and build hypotheses to understand how career adaptability serves as a moderator of the effects of different features of career changes on ratings of hypothetical employees' adapting effectiveness.

\section{Career Construction Theory}

Career construction theory describes the integration of vocational self-concepts into work roles (Savickas, 1997, 2002, 2005). Career adaptability is important for both the development and integration of one's vocational self-concept, and as such is a central construct in career construction theory. According to the career construction model of adaptation (see Hirschi et al., 2015; Savickas et al., 2009), control over one's career can be maintained through a process of managing social expectations (e.g., normative expectations for how one should prepare for, enter into, participate in, and exit from work roles). According to career construction theory, success in career development is maximized through a process of adaptation that occurs when people optimally integrate their personal needs with these social expectations (Savickas, 2002, 2005).

Career construction theory also suggests that there are individual differences that variously support peoples' attempts at integrating their self-concepts with their work roles (the outcomes thereof are described as "adaptation results"; Savickas, 2013; Savickas \& Porfeli, 2012). More specifically, people differ in terms of their "adaptivity" (i.e., their willingness or "adaptive readiness") and in terms of their "career adaptability" (i.e., their ability or "adaptability resources") to engage in "adapting responses" (i.e., capacities to behave in ways that address changes to one's environment). Thus, the career construction model of adaptation outlines a 
phased process by which adaptivity affects career adaptability, which then has influences on adapting responses and, in turn, adaptation results (see Hirschi et al., 2015; Rudolph et al., 2017b; Savickas, 2013; Savickas \& Porfeli, 2012; Tolentino et al., 2014).

\section{Literature Review and Hypothesis Development}

There are several studies that have investigated the role of career adaptability in the career transition process, for example studying re-employment following job loss, investigating career change behaviors following downsizing and restructuring, or exploring adaptation to first-time employment (i.e., school-to-work transitions). To this end, Koen et al. (2010) conducted a twowave study of $n=248$ unemployed people to investigate relationships between career adaptability dimensions, job search strategies, and reemployment success outcomes. Career adaptability was found to predict re-employment quality (i.e., higher needs-supplies fit and job satisfaction; lower turnover intentions) among those who had obtained employment eight-months following the baseline survey.

Along similar lines, Klehe et al. (2011) studied how downsizing influences career adaptive behaviors, and subsequent loyalty and exit reactions five months later in a sample of $n=$ 210 employees from a Dutch technical service organization that was undergoing downsizing to reduce $17 \%$ of its workforce. In this study, redundant employees were informed a full year before their final lay-off date, thus allowing for the influence of experiencing redundancy to be studied prior to actual involuntary attrition. At baseline, redundant employees (i.e., those who were informed of eventual layoff) reported engaging in more career adaptive behaviors (i.e., career planning and exploration) than non-redundant employees. At follow-up, career planning was found to positively predict employees' loyalty to the organization, whereas career exploration was negatively related to employees' loyalty, and positively related to employees' turnover intentions, job-search behaviors, and actual turnover behavior. 
Finally, Koen et al. (2012) developed a training intervention to increase university graduates career adaptability in the school-to-work transition. The intervention was successful at enhancing participants' levels of control and curiosity, two dimensions of career adaptability, over time. Moreover, participants who were employed six-months following the intervention reported higher levels of employment quality than did members of the control group who did not participate in the intervention. This study shows that career adaptability resources can exert an important influence on the success of career transitions and can specifically influence people's likelihood of obtaining quality employment opportunities over time.

Each of these reviewed studies supports the prediction from career construction theory that career adaptability is a self-regulatory competency that enables individuals to successfully address challenges that they encounter over the course of their careers - particularly those that are unfamiliar, complex, and/or ill-defined (Savickas \& Porfeli, 2012). Moreover, these studies support the ideas that career adaptability is both malleable and transactional, in that high levels of career adaptability are associated with (a) more proactive preparation for future career tasks (concern), (b) exercises in agency that serve one's own career development (control), (c) the exploration of new career opportunities and potential future selves (curiosity), and (d) the demonstration of the efficacy of one's abilities to manage career-related problems (confidence).

In the present study, we examined career adaptability as a moderator of the effects of different types of career changes (i.e., varying in terms of their involuntariness, radicality, and social undesirability) on ratings of hypothetical employees' adapting effectiveness. We base such examinations on predictions derived from career construction theory, specifically, according to the career construction model of adaptation (Hirschi et al., 2015; Savickas, 2005), the effectiveness of adapting responses involves the extent to which employees cope effectively and successfully perform adaptive behaviors that address changing conditions. We focused on 
involuntariness, radicality, and social undesirability as such changing conditions, as these have been identified in the vocational behavior literature as key characteristics of work transitions, career changes, and occupational mobility (Feldman \& Ng, 2007; Fouad \& Bynner, 2008).

Involuntariness describes employees' discretion or degree of control in initiating a career change (Fouad \& Bynner, 2008). For instance, unexpected layoffs typically mean that employees have to change jobs, organizations, or even occupations involuntarily. In contrast, other employees may search for better employment opportunities voluntarily. Radicality entails the extent to which employees have to acquire new knowledge, skills, and other attributes when they change jobs, organizations, or occupations (Fouad \& Bynner, 2008). For instance, an organizational consultant who retrains to become a kindergarden teacher is undergoing a radical career change, whereas an accountant who moves from an auditing role at a manufacturing company to the same role at a telecommunications company still performs similar tasks and thus does not experience a radical career change. Social undesirability refers to the extent to which the career change is associated with a decrease in normative occupational status or prestige (Fouad \& Bynner, 2008). For example, a corporate manager who becomes a custodian might be seen by others as experiencing an undesirable career change.

Based on career construction theory (Savickas, 1997, 2013), we expected that high levels of career adaptability are particularly important when career changes are involuntary, radical, and socially undesirable. The underlying reason for these expectations, is that involuntary, radical, and socially undesirable career changes are arguably more challenging than voluntary, nonradical, and socially desirable career changes and, thus, should be associated with generally lower adapting effectiveness (Fouad \& Bynner, 2008). However, in these difficult situations, employees with high career adaptability are more likely to be concerned and curious about their future work 
opportunities and to take control and show confidence when occupational challenges and setbacks arise (Zacher, 2014). Thus, we offer the following hypotheses:

Hypothesis 1: Career adaptability moderates the negative effect of involuntariness of career changes on perceptions of adapting effectiveness, such that the effect is weaker when career adaptability is high and stronger when career adaptability is low.

Hypothesis 2: Career adaptability moderates the negative effect of radicality of career changes on perceptions of adapting effectiveness, such that the effect is weaker when career adaptability is high and stronger when career adaptability is low.

Hypothesis 3: Career adaptability moderates the negative effect of social undesirability of career changes on perceptions of adapting effectiveness, such that the effect is weaker when career adaptability is high and stronger when career adaptability is low.

\section{Method}

\section{Pilot Study}

Participants and procedure. We initially developed and pilot tested a set of scenarios to serve as the basis for our experimental vignettes (see Table 1). In order to develop these vignettes, descriptions of career change scenarios were developed, based upon definitions and descriptions of different features of career changes derived from the literature (e.g., Feldman \& Ng, 2007; Fouad \& Bynner, 2008; Zacher, 2018) and, to manipulate career adaptability of hypothetical employees, based on items of the widely-used career adapt-ability scale (Savickas \& Porfeli, 2012). In particular, we operationalized low voluntariness (i.e., involuntariness) as career changes due to illness, accidents, and job market situations, whereas high voluntariness was operationalized as career changes due to pursuing one's interests, meaning of work, and dissatisfaction. High radicality career changes involved fundamental differences in knowledge, skills, and abilities required in the new as compared to the previous occupation, whereas low 
radicality does not entail such fundamental differences. A career change was deemed to be highly socially undesirable when it involved a loss of income and prestige, as well as negative evaluations by one's social environment. In contrast, a socially desirable career change did not involve such losses and negative social evaluations. Finally, career adaptability was manipulated with statements that referred to its four dimensions: concern, control, curiosity, and confidence (Savickas \& Porfeli, 2012).

To establish the validity of these vignettes $n=21$ participants $(n=12$ female and $n=9$ male; between 22 and 31 years of age, $M_{\text {age }}=26$ years, $S D=2.16$ years) were recruited through personal contacts. These participants read each vignette, and were instructed to categorize and rate each statement. More specifically, after reading each statement, participants categorized each into their respective dimensions (i.e., involuntariness, radicality, or social undesirability). Participants were also asked to rate the extent to which each scenario reflected a high or low level of the respective underlying construct (e.g., low career adaptability).

Results. For the involuntariness dimension, all statements (100\%) were correctly categorized, for the radicality dimension, 95\% were correctly categorized, and for the social undesirability dimension $90 \%$ were correctly categorized. Finally, for career adaptability, 90\% of the statements were categorized correctly. All statements with lower levels were rated significantly lower regarding the extent to which they reflect the respective construct compared to those with a higher level $(t \mathrm{~s}>-9.66, p \mathrm{~s}<.01)$. All statements and associated descriptive statistics from this pilot study can be found in Table 1. With sufficient evidence for the validity of these scenarios, we then proceeded to our primary study.

\section{Main Study}

Participants and procedure. We recruited a convenience sample of $n=54$ individuals from our professional networks to participate in our primary study. The sample was comprised of 
$n=33$ females and $n=20$ males ( $n=1$ did not indicate their gender), whose ages ranged between 24 and 69 years of age $\left(M_{\text {age }}=33.70\right.$ years, $S D=10.50$ years, $n=5$ did not indicate their age). Of the 54 participants, $n=49$ were currently employed, whereas $n=5$ were currently not employed. Of those employed, $n=16(32.6 \%)$ had a job tenure of less than 2 years, $n=14$ $(28.6 \%)$ had a job tenure of $2-10$ years, and $n=19(38.8 \%)$ had a job tenure of more than 10 years. Finally, $n=5(9.26 \%)$ of participants indicated that they had never undergone a career change, $n=23(42.59 \%)$ indicated undergoing one career change, $n=17(31.48 \%)$ two career changes, and $n=9(16.67 \%)$ indicated undergoing three career changes. In terms of education $n$ $=38$ participants $(70.4 \%)$ had at least a Bachelor's degree.

Using the vignettes developed in our pilot study, described above, we adopted a $2 \times 2 \times 2 \times 2$ fully-factorial within-person experimental vignette methodology (i.e., policy-capturing) design (Aguinis \& Bradley, 2014; Aiman-Smith et al., 2002). A flowchart outlining the study design can be found in Figure 1. More specifically, using the scenarios of hypothetical employees and their career changes depicted in Table 1, we manipulated involuntariness (high vs. low), radicality (high vs. low), and social undesirability (high vs. low) of career changes. In each vignette, we also manipulated the career adaptability (high vs. low) of the hypothetical employees. An example vignette, with manipulated levels annotated in square brackets, would be: "The person changed their occupation to better align their interests with their professional activities [low involuntariness]. The knowledge required in the new occupation is barely similar to the knowledge required in the previous occupation [high radicality]. The income in the new occupation is much lower than in the previous occupation [high social undesirability]. The person has pronounced abilities to explore their environment and to perceive different ways of doing things [high career adaptability]." 
Participants were instructed that each vignette depicted a hypothetical individual who was experiencing a job change. After reading each vignette, participants were asked to rate the adapting effectiveness of the hypothetical employee depicted therein. For each vignette, adapting effectiveness was measured with a single item: "How effectively do you think the employee is coping with the career change," which was rated on a 7-point scale ranging from $1=$ not effectively at all to $7=$ extremely effectively. The sample of $n=54$ participants rated each of the 16 vignettes on this measure, and thus provided a total of 864 ratings of adapting effectiveness. Because each of the scenarios was rated by all participants, we used mixed effects modeling procedures (Hofmann et al., 2000) to test our hypotheses while accounting for the nested structure of the data. All data and R code files to reproduce the results presented below are available in our online appendix: https://osf.io/te28b/.

\section{Results}

Table 2 shows the results of the mixed effects analyses predicting ratings of adapting effectiveness, and Table 3 shows model predicted means resulting from these analyses. An intercept-only model showed that all of the variance in adapting effectiveness ratings resided at the within-person level of analysis $\left(\mathrm{ICC}_{1}=-.02\right)$. Considering the variance components of this model, this negative $\mathrm{ICC}_{1}$ value is attributable to the within-person variance component $\left(\mathrm{MS}_{\mathrm{w}}=\right.$ 2.697) being 1.36 times greater than the between-person variance component $\left(\mathrm{MS}_{\mathrm{b}}=1.990\right)$. This observation is not entirely surprising given the within-person design adopted here (see also Bliese, 2000, p. 355 for an explanation of negative $\mathrm{ICC}_{1}$ values).

A second model (Table 2) showed that career adaptability had a positive effect on ratings of adapting effectiveness ( $B=2.17, p<.001)$, suggesting that higher (lower) levels of career adaptability were associated with higher (lower) adapting effectiveness. In contrast, ratings of adapting effectiveness were negatively predicted by involuntariness $(B=-.33, p<.001)$, 
radicality $(B=-.39, p<.001)$, and social undesirability $(B=-.73, p<.001)$, suggesting that lower (higher) levels of these variables were associated with lower (higher) adapting effectiveness. Thus, in general, the greater the involuntariness, radicality, and social undesirability of career changes, the lower the ratings of adapting effectiveness. This model explained $R^{2}=51.70 \%$ of the within-person variance in ratings of adapting effectiveness. To further understand the contributions of these four variables to the prediction of such ratings, we conducted a multilevel dominance analysis to parse the unique contributions of each predictor to the within-person variance explained (see Luo \& Azen, 2013). This analysis suggests that career adaptability is responsible for the majority of the within-person variance explained by this model $\left(\% R^{2}=86.11 \%\right.$ of the $R^{2}=51.70 \%$ variance explained in ratings of adapting effectiveness), with involuntariness, radicality, and social undesirability accounting for $2.56 \%, 9.54 \%$, and $1.78 \%$ of the within-person variance explained, respectively

According to Hypothesis 1, the negative effect of involuntariness of career changes on ratings of adapting effectiveness is weaker when career adaptability is high and stronger when career adaptability is low. Table 2 shows that the interaction between involuntariness and career adaptability was significant $(B=-.32, p=.033)$. However, in contrast to our hypothesized expectations, the effect of involuntariness was more strongly negative for employees with high as compared to low career adaptability (see Figure $2 \&$ Table 3 ). Thus, Hypothesis 1 was not supported.

Hypothesis 2 suggests that the negative effect of radicality of career changes on ratings of adapting effectiveness is weaker when career adaptability is high and stronger when career adaptability is low. Table 2 shows that the interaction between radicality and career adaptability was significant $(B=.58, p=.033)$. The pattern of this interaction was consistent with 
expectations (see Figure $3 \&$ Table 3); high levels of career adaptability buffered the negative effect of radicality on adapting effectiveness. Thus, Hypothesis 2 was supported.

Finally, Hypothesis 3 states that the negative effect of social undesirability of career changes on ratings of adapting effectiveness is weaker when career adaptability is high and stronger when career adaptability is low. As shown in Table 2, the interaction between social undesirability and career adaptability was not significant $(B=.04, p=.781)$. Thus, Hypothesis 3 was not supported (see also Table 3).

\section{Sensitivity analysis}

As a check on the robustness of our findings, we additionally considered models controlling for employment status (i.e., employed vs. unemployed) and number of career changes experienced. There were no substantive differences observed between these sensitivity models and the main results reported here; the conclusions with respect to both main and interactive effects were exactly the same. Thus, we are confident that these two demographic variables are not unduly influencing our conclusions. Given this observation, and for the sake of manuscript space, we do not report these analyses here, however data and code to reproduce these analyses are available in our online appendix.

\section{Discussion}

Most research on career adaptability has neglected the external conditions that may interact with employees' career adaptability to predict adapting effectiveness. Furthermore, the majority of studies on career adaptability use correlational designs, which do not allow firm conclusions about causality. The goal of our study, therefore, was to examine whether high levels of career adaptability are perceived to be particularly useful when employees' career changes are involuntary, radical, and socially undesirable. Findings of our study were mixed. Career adaptability appears to be seen as especially beneficial in terms of adapting effectiveness when 
employees undergo a radical career change, that is, when the new occupation requires fundamentally new knowledge, skills, and abilities compared to the previous occupation. These results are at least partially consistent with research on the role of career adaptability for people undergoing career changes (e.g., Klehe et al., 2011 found that employees forced to undergo career changes engage in more career adaptive behaviors). In contrast, career adaptability was not viewed as having an impact on the negative effect of the social undesirability of career changes on adapting effectiveness. Moreover, a surprising finding was that high career adaptability was seen as somewhat more beneficial when career changes were voluntary as compared to involuntary.

There are several possible explanations for these conflicting findings. On the one hand, our observation of a non-significant moderation effect of career adaptability on the negative effect of social undesirability on adapting effectiveness may be due to raters' perceptions of the existential importance of income and social evaluations. That is, while career adaptability seems to be perceived as helpful to employees when dealing with fundamental changes in knowledge, skills, and abilities (i.e., radicality), career adaptability may be viewed as less helpful in terms of factors that cannot be changed easily. Income and social prestige are both relatively stable features of occupations over time and thus, it may be understood that additional career changes would be necessary to improve these factors.

On the other hand, our observation of effects in the opposite direction of that predicted for involuntariness might be due to perceived personal and contextual resources available during voluntary and involuntary career changes. Specifically, voluntary career changes may be viewed in terms of gains in resources, such as intrinsic motivation and autonomy, which allow individuals to capitalize on their career adaptability behaviors, thus leading to greater perceived adapting effectiveness. In contrast, involuntary career changes should be more likely to involve 
losses in personal and contextual resources, such as heightened negative affect and changes in social relations (Fouad \& Bynner, 2008). Such losses in resources may be viewed as difficult to compensate for through high career adaptability alone. These mixed and unexpected findings beg for future empirical elaboration, and we hope that this study inspires such efforts. These findings also have some interesting implications for theory and practice, which we will discuss next.

\section{Implications for Theory and Practice}

Our study is one of the first to experimentally evaluate a key tenet of career construction theory - that career adaptability is efficient for managing career related transitions and traumas, and that people are readily capable of recognizing this in others. Our study contributes to the continued development of career construction theory in two important ways. First, by calling into question the prediction that career adaptability is generally a resource for supporting individuals who are undergoing career changes. Our findings suggest that people perceive the utility of career adaptability as a resource for change quite differently, with career adaptability seen as being mostly important during radical career changes, but not during involuntary and socially undesirable changes. Second, our findings underscore the importance of interactions between career actors and situations as postulated by career construction theory (Savickas, 1997). While both career adaptability and the nature of career changes by themselves explain variability in adapting effectiveness, career adaptability clearly does not manifest its effects independent of the nature of career changes. Thus, theories such as the career construction model of adaptation should be supplemented with conditional, person-environment interaction effect predictions. To this end, future theoretical extensions of career construction theory may especially benefit from integrating propositions from the theory of work adjustment (Dawis \& Lofquist, 1984).

In terms of practical implications, this study suggests that people are able to recognize the positive role that career adaptability plays across various types of career transitions. These results 
hint at the possibility that career counselors could be trained to recognize and identify career adaptability to provide better guidance to their clients, for example, by encouraging them to engage in more career adaptive behaviors. We thus encourage researchers to "build out" the vignettes we present here into full case studies, which could be useful in the development of such training programs for career counselors. Moreover, the fact that our sample did not have formal training in vocational guidance suggests that even lay people recognize the value of career adaptability for others in scenarios where they are tasked with considering narratives of career change.

\section{Limitations}

Some limitations to the present work bear additional considerations. First, we relied on a relatively small convenience sample. Although such samples are not uncommon for experimental vignette methodology studies (e.g., Ohme \& Zacher, 2015) and our within-person design allows for efficient tests of the relationships we propose here, future research should consider a broader and more demographically representative sample of the population. Second, experimental vignette studies have been criticized for having high internal but low external and ecological validity (Aguinis \& Bradley, 2014). We consider this a tradeoff between, on the one hand, being able to isolate the specific features of career change under consideration here, while on the other hand recognizing that the decision-making context does not exactly map onto the "real world." To this end, one of the goals of this study was to understand how people external to those undergoing career transitions recognize the importance that career adaptability plays in managing the demands of such transitions. However, it is important to point out that in our experimental vignette study, we could not investigate all aspects of this process of "recognition," rather we focus on how participants in our study perceived career adaptability and integrated such perceptions into their ratings of adapting effectiveness. Indeed, recognition of the importance of 
career adaptability could take multiple forms, and researchers are especially encouraged to consider other ways in which such recognitions may occur in future research (e.g., behavioral manifestations, such as the provision of feedback or advice to individuals undergoing career changes). Ultimately, we feel that these results are informative to the advancement of career construction theory and hope that future work will continue to consider the moderating role of career adaptability in the process of actual, experienced career changes.

Third, although we did ask participants to indicate how many career changes they had undergone, we did not assess what form of career change participants had experienced (i.e., in terms of voluntariness, radicality, or social desirability). It is possible that people's own experiences with career changes that might be considered involuntary, radical, and/or socially undesirable could serve to frame their consideration and evaluation of the hypothetical individuals contained within our vignettes. By simply capturing the number of career changes experienced, we are missing the level of nuance necessary to completely ascertain how this would influence our results. However, it is important to note that our sensitivity analysis suggests that our results did not change when controlling for the number of career changes experienced. Fourth, and also related to the last point, we did not address people's own level of career adaptability as an individual difference. A similar argument could be made that individuals with varying levels of career adaptability could be more or less inclined to recognize such characteristics in others, like those hypothetical individuals contained within our vignettes. Future research of this type should thus consider both experiential and individual difference variables to rule out these possibilities.

Fifth, participants in our study were tasked with considering a number of hypothetical situations and providing ratings of adapting effectiveness across those situations. Thus, while we can model variability across such ratings in a relative sense, we cannot capture the accuracy of 
such ratings in an absolute sense (e.g., against a "true score"; Sulsky \& Balzer, 1988), and it was not our goal to do so. Future research may consider whether it is possible and of value to consider rating accuracy as an additional criterion when designing experimental vignette studies. Finally, although we manipulated career adaptability by varying aspects of its four dimensions, we are unable to separately consider these four dimensions in our analyses. Future research should therefore consider the operation of the four dimensions of career adaptability against one-another to determine their (relative) contribution to our understanding of adapting effectiveness.

\section{Directions for Future Research}

Given these findings, we see three distinct opportunities for future research. First, we ignored the role of adaptivity (i.e., adaptive readiness) and instead focused solely on conditions that lead to career changes. Future experimental vignette studies may consider adaptivity, for example, by manipulating various traits related to the willingness to meet problems presented by vocational development tasks (see Hirschi et al., 2015). Second, future research could consider additional outcomes beyond ratings of adapting effectiveness (i.e., those related to adaptation, e.g., career satisfaction, vocational identity, subjective well-being). Finally, future research should consider an enhanced array of personal characteristics (e.g., the experience of different forms of career change; individual differences in career adaptability) as additional simple and/or conditional influences.

\section{Conclusions}

Based upon predictions from career construction theory, our vignette study suggests that career adaptability can be seen as an important resource for managing radical career changes. Although mixed support was found for other types of career changes, this study contributes to a growing body of evidence that career adaptability is an important psychosocial resource for managing career change. Importantly, our experimental vignette study shows that individuals are 
both capable of recognizing those characteristics of career adaptable individuals, and that such perceived characteristics translate into an understanding of what makes for more or less successful career changes. This study thus contributes to the extension of career construction theory and presents interesting new possibilities for the development of training programs for career counselors. Our hope is that this study inspires future research to better understand the interplay between career adaptability and different types of career transitions, and we challenge future researchers to more closely consider how career adaptability interacts with such transitions to affect career development outcomes. 


\section{Compliance with Ethical Standards}

Conflict of Interest Statement. On behalf of all authors, the corresponding author states that there is no conflict of interest.

Ethics Approval Statement. This study was granted exemption by [blinded for peer review] ethics committee. This study was performed in accordance with the ethical standards as laid down in the 1964 Declaration of Helsinki and its later amendments or comparable ethical standards. Informed consent was given, and participants were informed of the topic, voluntariness of participation, and anonymity of data prior to participation.

Data Availability Statement. The datasets generated and analyzed during the current study are available in the Open Science Framework (OSF) repository: https://osf.io/te28b/ 


\section{References}

Aguinis, H., \& Bradley, K. J. (2014). Best practice recommendations for designing and implementing experimental vignette methodology studies. Organizational Research Methods, 17, 351-371. https://doi.org/10.1177/1094428114547952

Aiman-Smith, L., Scullen, S. E., \& Barr, S. H. (2002). Conducting studies of decision making in organizational contexts: A tutorial for policy-capturing and other regression-based techniques. Organizational Research Methods, 5, 388-414. https://doi.org/10.1177/109442802237117

Bliese, P. D. (2000). Within-group agreement, non-independence, and reliability: Implications for data aggregation and analysis. In K. J. Klein \& S. W. J. Kozlowski (Eds.), Multilevel theory, research, and methods in organizations: Foundations, extensions, and new directions (pp. 349-381). Jossey-Bass.

Blustein, D. L., Kozan, S., \& Connors-Kellgren, A. (2013). Unemployment and underemployment: A narrative analysis about loss. Journal of Vocational Behavior, 82, 256-265. https://doi.org/10.1016/j.jvb.2013.02.005

Brown, S. D., \& Lent, R. W. (2016). Vocational psychology: Agency, equity, and well-being. Annual Review of Psychology, 67, 541-565. https://doi.org/10.1146/ annurev-psych-122414-033237.

Chudzikowski, K. (2012). Career transitions and career success in the 'new'career era. Journal of Vocational Behavior, 81, 298-306. https://doi.org/10.1016/j.jvb.2011.10.005

Dawis, R. V., \& Lofquist, L. H. (1984). A psychological theory of work adjustment. University of Minnesota Press. 
Eby, L. T., \& Buch, K. (1995). Job loss as career growth: Responses to involuntary career transitions. Career Development Quarterly, 44, 26-42. https://doi.org/10.1002/j.21610045.1995.tb00526.x

Feldman, D., \& Ng, T. (2007). Careers: Mobility, embeddedness, and success. Journal of Management, 33, 350-377. https://doi.org/10.1177/0149206307300815

Fouad, N. A., \& Bynner, J. (2008). Work transitions. American Psychologist, 63, 241-251. https://doi.org/10.1037/0003-066X.63.4.241

Heppner, M. J., Multon, K. D., \& Johnston, J. A. (1994). Assessing psychological resources during career change: Development of the Career Transitions Inventory. Journal of Vocational Behavior, 44, 55-74. https://doi.org/10.1006/jvbe.1994.1004

Hirschi, A., Herrmann, A., \& Keller, A. C. (2015). Career adaptivity, adaptability, and adapting: A conceptual and empirical investigation. Journal of Vocational Behavior, 87, 1-10. https://doi.org/10.1016/j.jvb.2014.11.008

Hofmann, D. A., Griffin, M. A., \& Gavin, M. B. (2000). The application of hierarchical linear modeling to organizational research. In K. Klein \& S. W. J. Kozlowski (Eds.), Multilevel theory, research, and methods in organizations (pp. 467-511). Jossey-Bass.

Klehe, U. C., Zikic, J., Van Vianen, A. E. M., \& De Pater, I. E. (2011). Career adaptability, turnover and loyalty during organizational downsizing. Journal of Vocational Behavior, 79, 217-229. https://doi.org/10.1016/j.jvb.2011.01.004.

Koen, J., Klehe, U. C., Van Vianen, A. E., Zikic, J., \& Nauta, A. (2010). Job-search strategies and reemployment quality: The impact of career adaptability. Journal of Vocational Behavior, 77, 126-139. https://doi.org/10.1016/j.jvb.2010.02.004.

Koen, J., Klehe, U. C., \& Van Vianen, A. E. M. (2012). Training career adaptability to facilitate a successful school-to-work transition. Journal of Vocational Behavior, 81, 
395-408. http://doi.org/10.1016/j.jvb.2012.10.003

Latack, J. C. (1984). Career transitions within organizations: An exploratory study of work, nonwork, and coping strategies. Organizational Behavior and Human Performance, 34 , 296-322. https://doi.org/10.1016/0030-5073(84)90041-2

Latack, J. C., Kinicki, A. J., \& Prussia, G. E. (1995). An integrative process model of coping with job loss. Academy of Management Review, 20, 311-342.

https://doi.org/10.5465/amr.1995.9507312921

Luo, W., \& Azen, R. (2013). Determining predictor importance in hierarchical linear models using dominance analysis. Journal of Educational and Behavioral Statistics, 38, 3-31. https://doi.org/10.3102/1076998612458319

Ohme, M., \& Zacher, H. (2015). Job performance ratings: The relative importance of mental ability, conscientiousness, and career adaptability. Journal of Vocational Behavior, 87, 161-170. https://doi.org/10.1016/j.jvb.2015.01.003

Rigotti, T., Korek, S., \& Otto, K. (2014). Gains and losses related to career transitions within organisations. Journal of Vocational Behavior, 84, 177-187. https://doi.org/10.1016/j.jvb.2013.12.006

Rudolph, C. W., Lavigne, K. N., Katz, I. M., \& Zacher, H. (2017a). Linking dimensions of career adaptability to adaptation results: A meta-analysis. Journal of Vocational Behavior, 102, 151-173. https://doi.org/10.1016/j.jvb.2017.06.003

Rudolph, C. W., Lavigne, K. N., \& Zacher, H. (2017b). Career adaptability: A meta-analysis of relationships with measures of adaptivity, adapting responses, and adaptation results. Journal of Vocational Behavior, 98, 17-34. https://doi.org/10.1016/j.jvb.2016.09.002 
Savickas, M. L. (1997). Career adaptability: An integrative construct for life-span, life-space theory. Career Development Quarterly, 45, 247-259. https://doi.org/10.1002/j.21610045.1997.tb00469.x

Savickas, M. L. (2002). Career construction: A developmental theory of vocational behavior. In D. Brown (Ed.), Career choice and development (4 ${ }^{\text {th }}$ ed., pp. 149-205). Jossey-Bass.

Savickas, M. L. (2005). The theory and practice of career construction. In S. D. Brown \& R. W. Lent (Eds.), Career development and counseling: Putting theory and research to work (pp. 42-70). Wiley.

Savickas, M. L. (2013). Career construction theory and practice. In R. W. Lent \& S. D. Brown (Eds.), Career development and counselling: Putting theory and research into work (2nd ed., pp. 147-183). Wiley.

Savickas, M. L., Nota, L., Rossier, J., Dauwalder, J. P., Duarte, M. E., Guichard, J., Soresi, S., Van Esbroeck, R., \& Van Vianen, A. E. (2009). Life designing: A paradigm for career construction in the $21^{\text {st }}$ century. Journal of Vocational Behavior, 75, 239-250. https://doi.org/10.1016/j.jvb.2009.04.004

Savickas, M. L., \& Porfeli, E. J. (2012). Career Adapt-Abilities Scale: Construction, reliability, and measurement equivalence across 13 countries. Journal of Vocational Behavior, 80, 661-673. https://doi.org/10.1016/j.jvb.2012.01.011

Sulsky, L. M., \& Balzer, W. K. (1988). Meaning and measurement of performance rating accuracy: Some methodological and theoretical concerns. Journal of Applied Psychology, 73(3), 497-506. http://dx.doi.org/10.1037/0021-9010.73.3.497

Tolentino, L. R., Garcia, P. R. J. M., Lu, V. N., Restubog, S. L. D., Bordia, P., \& Plewa, C. (2014). Career adaptation: The relation of adaptability to goal orientation, proactive 
personality, and career optimism. Journal of Vocational Behavior, 84, 39-48. https://doi.org/10.1016/j.jvb.2013.11.004.

Young, J. B., \& Rodgers, R. F. (1997). A model of radical career change in the context of psychosocial development. Journal of Career Assessment, 5, 167-182. https://doi.org/10.1177/106907279700500204

Zacher, H. (2014). Career adaptability predicts subjective career success above and beyond personality traits and core self-evaluations. Journal of Vocational Behavior, 84, 21-30. https://doi.org/10.1016/j.jvb.2013.10.002

Zacher, H. (2018). Berufliche Veränderungen: Wenn Erwerbstätige sich neu orientieren [Occupational changes: When workers reorient themselves]. In S. Kauffeld \& D. Spurk (Eds.), Handbuch Laufbahnmanagement und Karriereplanung. Springer. https://doi.org/10.1007/978-3-662-45855-6_14-1 
Table 1. Pilot Study Results: Vignette Statements and Descriptive Statistics

\begin{tabular}{|c|c|c|c|c|c|}
\hline Career Change & Dimension & Statement & Level $^{\mathbf{a}}$ & $\mathbf{M}$ & SD \\
\hline \multicolumn{6}{|l|}{ Involuntariness } \\
\hline & Interests & $\begin{array}{l}\text { The person changed their occupation to better align their interests with their professional } \\
\text { activities. }\end{array}$ & 1 & 1.35 & 0.80 \\
\hline & Illness & $\begin{array}{l}\text { The person changed their occupation because they cannot work in their previous occupation due } \\
\text { to illness. }\end{array}$ & 2 & 7.00 & 0.00 \\
\hline & Meaning & The person changed their occupation to experience greater meaningfulness in their work. & 1 & 1.24 & 0.44 \\
\hline & Accident & $\begin{array}{l}\text { The person changed their occupation because they cannot work in their previous occupation due } \\
\text { to an accident. }\end{array}$ & 2 & 7.00 & 0.00 \\
\hline & Dissatisfaction & The person changed their occupation due to long lasting dissatisfaction with their occupation. & 1 & 2.38 & 1.28 \\
\hline & Job market & The person changed their occupation due to the difficult job market situation. & 2 & 5.95 & 0.80 \\
\hline \multicolumn{6}{|c|}{ C } \\
\hline & Knowledge & $\begin{array}{l}\text { The knowledge required in the new occupation is very similar to the knowledge required in the } \\
\text { previous occupation. }\end{array}$ & 1 & 2.10 & 1.55 \\
\hline & & $\begin{array}{l}\text { The knowledge required in the new occupation is barely similar to the knowledge required in the } \\
\text { previous occupation. }\end{array}$ & 2 & 5.20 & 1.82 \\
\hline & Abilities & $\begin{array}{l}\text { The necessary abilities in the new occupation barely differ from the abilities in the previous } \\
\text { occupation. }\end{array}$ & 1 & 2.10 & 1.04 \\
\hline & & $\begin{array}{l}\text { The necessary abilities in the new occupation differ very much from the abilities in the previous } \\
\text { occupation. }\end{array}$ & 2 & 5.85 & 1.39 \\
\hline & Skills & $\begin{array}{l}\text { The necessary skills in the new occupation barely differ from the skills in the previous } \\
\text { occupation. }\end{array}$ & 1 & 1.71 & 0.56 \\
\hline & & $\begin{array}{l}\text { The necessary skills in the new occupation differ very much from the skills in the previous } \\
\text { occupation. }\end{array}$ & 2 & 6.05 & 1.07 \\
\hline \multirow{2}{*}{\multicolumn{6}{|c|}{$\begin{array}{l}\text { Social } \\
\text { Undesirability }\end{array}$}} \\
\hline & & & & & \\
\hline & & The income in the new occupation is much lower than in the previous occupation. & 2 & 6.19 & 0.75 \\
\hline & Prestige & The change in occupation is evaluated as an advancement in society. & 1 & 2.24 & 0.75 \\
\hline & & The change in occupation is evaluated as a downward movement in society. & 2 & 6.25 & 0.64 \\
\hline & $\begin{array}{l}\text { Social } \\
\text { environment }\end{array}$ & The social environment evaluates the change in occupation positively. & 1 & 1.90 & 0.62 \\
\hline & & The social environment evaluates the change in occupation negatively. & 2 & 6.33 & 0.66 \\
\hline \multicolumn{6}{|l|}{ Career Adaptability } \\
\hline & Concern & $\begin{array}{l}\text { The person has a lack of abilities to reflect on their professional development and to plan it based } \\
\text { on personal goals. }\end{array}$ & 1 & 1.85 & 0.67 \\
\hline & & $\begin{array}{l}\text { The person has pronounced abilities to reflect on their professional development and to plan it } \\
\text { based on personal goals. }\end{array}$ & 2 & 6.48 & 0.51 \\
\hline
\end{tabular}




\begin{tabular}{|c|c|c|c|c|}
\hline \multirow[t]{2}{*}{ Control } & $\begin{array}{l}\text { The person has a lack of abilities to make responsible decisions for themselves and to remain } \\
\text { optimistic. }\end{array}$ & 1 & 1.68 & 0.48 \\
\hline & $\begin{array}{l}\text { The person has pronounced abilities to make responsible decisions for themselves and to remain } \\
\text { optimistic. }\end{array}$ & 2 & 6.50 & 0.51 \\
\hline \multirow[t]{2}{*}{ Curiosity } & $\begin{array}{l}\text { The person has a lack of abilities to explore their environment and to perceive different ways of } \\
\text { doing things. }\end{array}$ & 1 & 1.86 & 0.79 \\
\hline & $\begin{array}{l}\text { The person has pronounced abilities to explore their environment and to perceive different ways } \\
\text { of doing things. }\end{array}$ & 2 & 5.86 & 1.06 \\
\hline \multirow[t]{2}{*}{ Confidence } & $\begin{array}{l}\text { The person has a lack of abilities to perform tasks efficiently and to overcome obstacles with } \\
\text { confidence. }\end{array}$ & 1 & 1.95 & 0.74 \\
\hline & $\begin{array}{l}\text { The person has pronounced abilities to perform tasks efficiently and to overcome obstacles with } \\
\text { confidence. }\end{array}$ & 2 & 6.38 & 0.50 \\
\hline
\end{tabular}

Note. $N=21 .{ }^{\text {a }} 1=$ low level, $2=$ high level. Participants were asked to rate each statement on a 7-point scale $(1=$ very low, $7=$ very high $)$. $M=$ mean, $S D=$ standard deviation. 
Table 2. Results of Multilevel Analyses Predicting Ratings of Adapting Effectiveness

\begin{tabular}{|c|c|c|c|c|c|c|c|c|c|}
\hline & \multicolumn{3}{|c|}{$\begin{array}{c}\text { Ratings of } \\
\text { Adapting Effectiveness }\end{array}$} & \multicolumn{3}{|c|}{$\begin{array}{c}\text { Ratings of } \\
\text { Adapting Effectiveness }\end{array}$} & \multicolumn{3}{|c|}{$\begin{array}{c}\text { Ratings of } \\
\text { Adapting Effectiveness }\end{array}$} \\
\hline & $B$ & S.E. & $p$ & $B$ & S.E. & $p$ & $B$ & S.E. & $p$ \\
\hline \multicolumn{10}{|l|}{ Fixed Parts } \\
\hline (Intercept) & 4.46 & 0.06 & $<.001$ & 4.09 & 0.09 & $<.001$ & 4.17 & 0.11 & $<.001$ \\
\hline Career Adaptability & & & & 2.17 & 0.08 & $<.001$ & 2.02 & 0.15 & $<.001$ \\
\hline Involuntariness & & & & -0.33 & 0.08 & $<.001$ & -0.17 & 0.11 & .116 \\
\hline Radicality & & & & -0.39 & 0.08 & $<.001$ & -0.68 & 0.11 & $<.001$ \\
\hline Social Undesirability & & & & -0.73 & 0.08 & $<.001$ & -0.75 & 0.11 & $<.001$ \\
\hline Career Adaptability by Involuntariness & & & & & & & -0.32 & 0.15 & .033 \\
\hline Career Adaptability by Radicality & & & & & & & 0.58 & 0.15 & $<.001$ \\
\hline Career Adaptability by Social Undesirability & & & & & & & 0.04 & 0.15 & .781 \\
\hline \multicolumn{10}{|l|}{ Random Parts } \\
\hline$\sigma^{2}$ & \multicolumn{3}{|c|}{2.654} & \multicolumn{3}{|c|}{1.234} & \multicolumn{3}{|c|}{1.209} \\
\hline$\tau_{00, \mathrm{ID}}$ & \multicolumn{3}{|c|}{0.000} & \multicolumn{3}{|c|}{0.047} & \multicolumn{3}{|c|}{0.049} \\
\hline $\mathrm{N}_{\text {ID }}$ & \multicolumn{3}{|c|}{54} & \multicolumn{3}{|c|}{54} & \multicolumn{3}{|c|}{54} \\
\hline $\mathrm{ICC}_{\mathrm{ID}}$ & \multicolumn{3}{|c|}{0.000} & \multicolumn{3}{|c|}{0.037} & \multicolumn{3}{|c|}{0.039} \\
\hline Observations & \multicolumn{3}{|c|}{864} & \multicolumn{3}{|c|}{864} & \multicolumn{3}{|c|}{864} \\
\hline $\mathrm{R}^{2}$ Between $/ \mathrm{R}^{2}$ Within & & & & \multicolumn{3}{|c|}{$.250 / .517$} & \multicolumn{3}{|c|}{$.250 / .526$} \\
\hline
\end{tabular}


Table 3. Model Predicted Means for Ratings of Adapting Effectiveness

\begin{tabular}{|c|c|c|c|c|c|}
\hline $\begin{array}{c}\text { Career } \\
\text { Adaptability Level }\end{array}$ & $\begin{array}{c}\text { Career } \\
\text { Change Level }\end{array}$ & $\begin{array}{l}\text { Predicted } \\
\text { Mean }\end{array}$ & $\mathrm{SE}$ & $\begin{array}{l}95 \% \mathrm{CI} \\
\text { Lower }\end{array}$ & $\begin{array}{l}95 \% \mathrm{CI} \\
\text { Upper }\end{array}$ \\
\hline \multirow[t]{2}{*}{ Low Career Adaptability } & Low Involuntariness & 4.17 & 0.11 & 3.95 & 4.38 \\
\hline & High Involuntariness & 4.00 & 0.11 & 3.78 & 4.22 \\
\hline \multirow[t]{2}{*}{ High Career Adaptability } & Low Involuntariness & 6.19 & 0.11 & 5.97 & 6.41 \\
\hline & High Involuntariness & 5.70 & 0.11 & 5.49 & 5.92 \\
\hline \multirow[t]{2}{*}{ Low Career Adaptability } & Low Radicality & 4.17 & 0.11 & 3.95 & 4.38 \\
\hline & High Radicality & 3.49 & 0.11 & 3.28 & 3.71 \\
\hline \multirow[t]{2}{*}{ High Career Adaptability } & Low Radicality & 6.19 & 0.11 & 5.97 & 6.41 \\
\hline & High Radicality & 6.09 & 0.11 & 5.88 & 6.31 \\
\hline \multirow[t]{2}{*}{ Low Career Adaptability } & Low Social Undesirability & 4.17 & 0.11 & 3.95 & 4.38 \\
\hline & High Social Undesirability & 3.42 & 0.11 & 3.20 & 3.63 \\
\hline \multirow[t]{2}{*}{ High Career Adaptability } & Low Social Undesirability & 6.19 & 0.11 & 5.97 & 6.41 \\
\hline & High Social Undesirability & 5.48 & 0.11 & 5.27 & 5.70 \\
\hline
\end{tabular}


Figure 1. Flowchart of the Study Design and Procedures

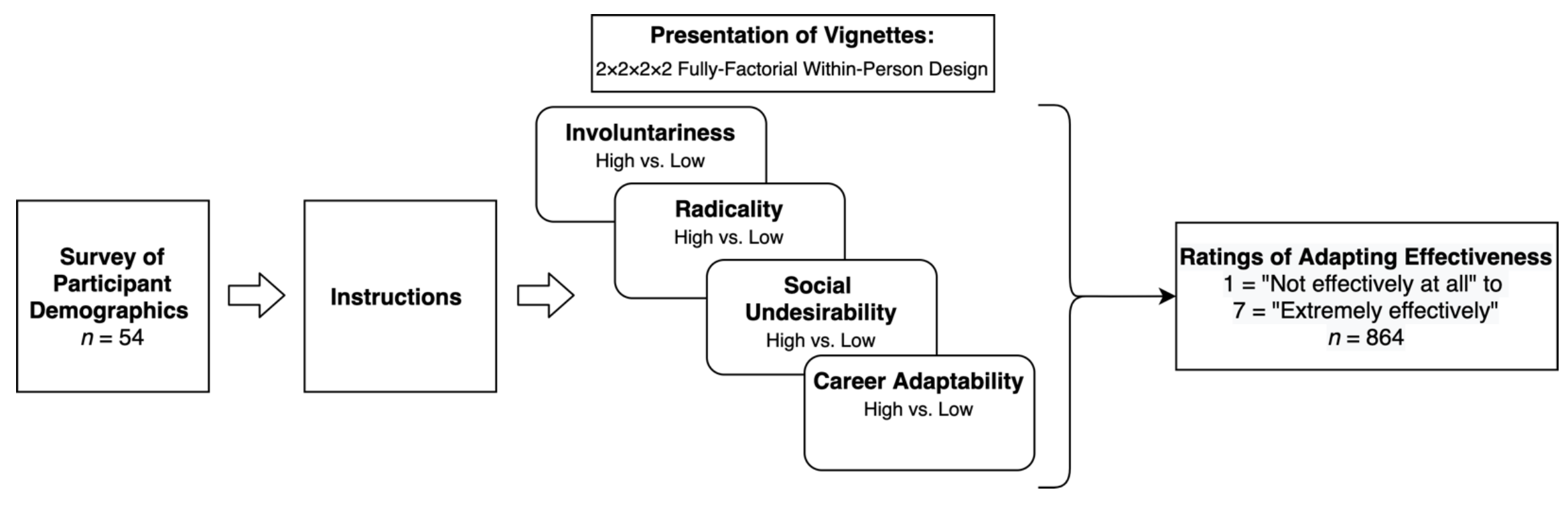


Figure 2. Effect of Involuntary Career Changes on Ratings of Adapting Effectiveness Moderated by Career Adaptability

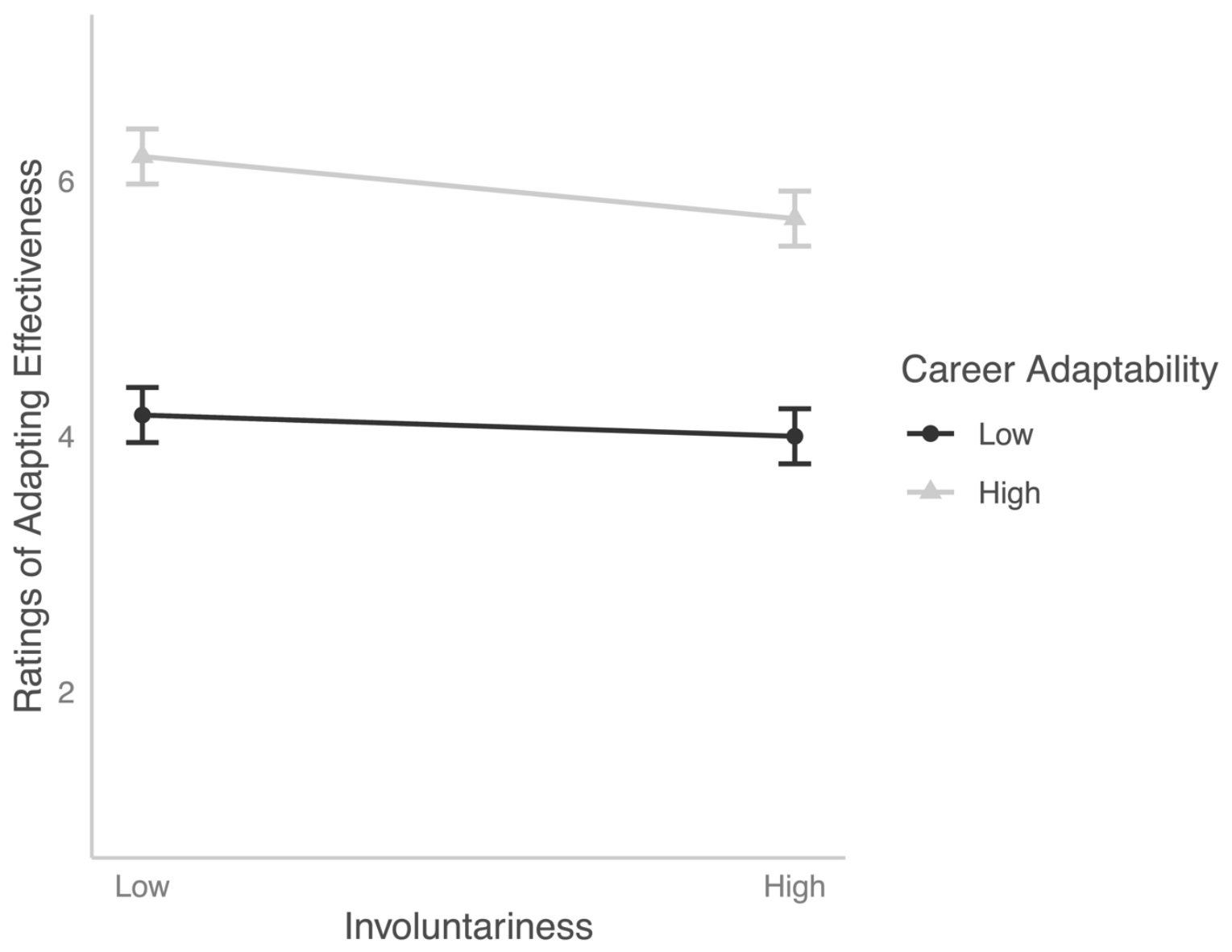

Note. Error bars represent $95 \%$ confidence intervals. 
Figure 3 Effect of Radical Career Changes on Ratings of Adapting Effectiveness Moderated by Career Adaptability

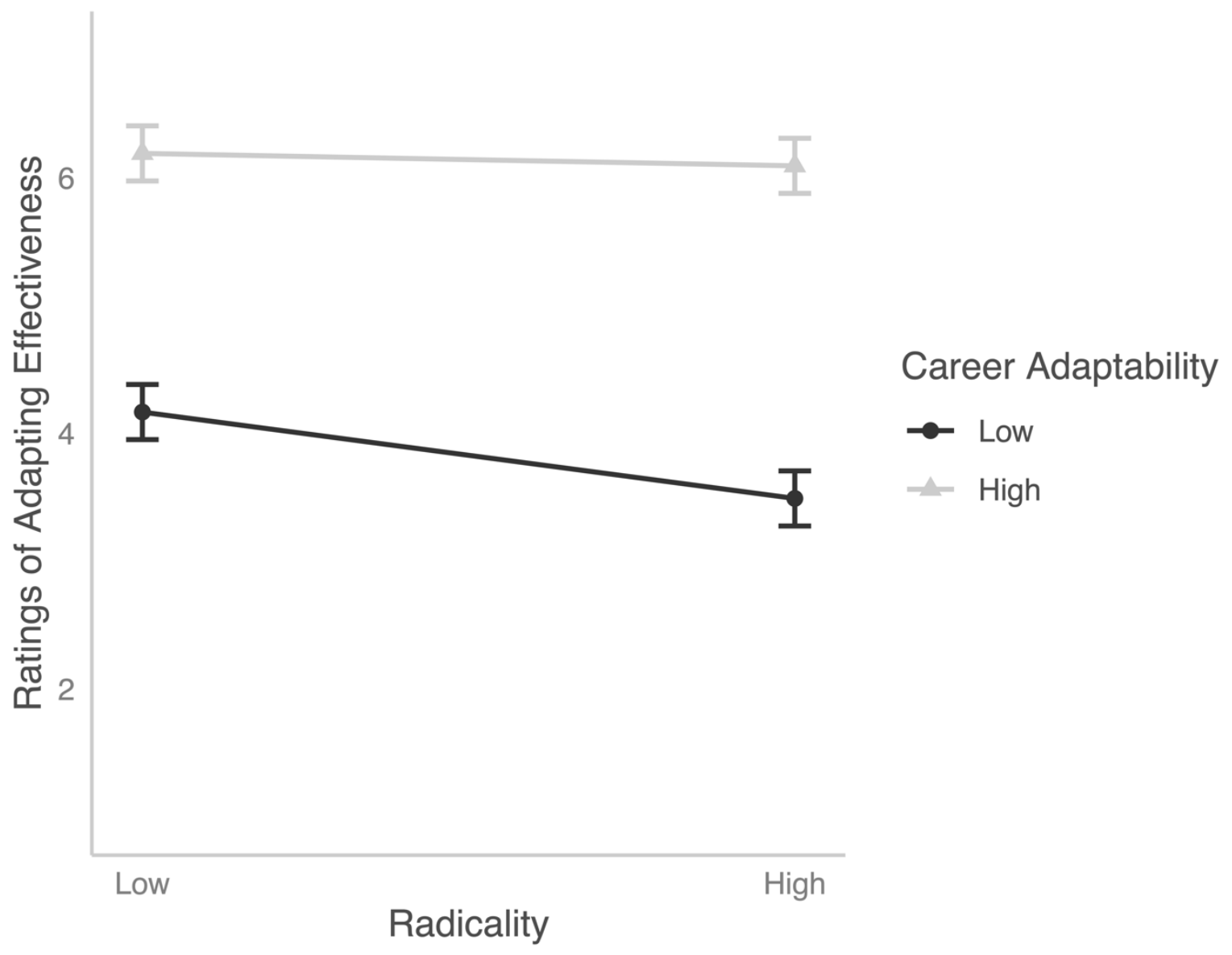

Note. Error bars represent $95 \%$ confidence intervals. 